\title{
Pitch and gender in voice training: new methodological directions
}

\author{
Jane Boston
}

\section{The gendering of pitch}

In this short essai, I lay out a number of practice-led insights about the gendered perception of the materiality of pitch. The research sits within a wider body of work that applies both feminist and gender theory to voice practice. Theories about the ways in which 'individuality and the resonances of our gestures are carried in the vocalic bodies we emanate' are particularly relevant to this discussion about perceptions of difference (Bonenfant 2010, p. $77)$.

Voice in the public domain is highly contested. Historically, it has been dominated by the male voice. Professor of Classics at Cambridge, Mary Beard, traces the imbalance as far back as ancient Greece:

What interests me is the relationship between [the] classic Homeric moment of silencing a woman and some of the ways in which women's voices are not publicly heard in our own contemporary culture, and in our own politics from the front bench to the shop floor. (2017, p. 6)

Beard suggests it is not only a matter of who is permitted to speak in the public domain, but also a question of the gendered stereotypes used in the descriptions about those who do speak. Beard argues that some of the terminology attributed to the public voice of women in the nineteenth century is problematic. Henry James, for example, made it clear where he stood on women's voices when he wrote about the "polluting, contagious and socially destructive effect of women's voices... thundering about the "thin nasal tones" of women's public speech' (cited in Beard 2017, p. 29).

Judgements associated with the pitch and tonal quality of women's voices, persist to this day. This, Beard notes, is in marked contrast to the positive attention given to the male voice: 'It is still the case that when listeners hear a female voice, they do not hear a voice that connotes authority; or rather they have not learned how to hear authority in it' (Beard 2017, p. 30).

Both sets of perceptions are based on outmoded stereotypes associated with the social constructs of gender. As Beard suggests, they are just that, constructs, and can be re-learnt. My studio practice - in drama school settings and in professional rehearsal-raises questions about some of the dominant social value judgements of gender as I have experienced and observed them as a voice practitioner over the past thirty years. In reframing the work, I aim to better refine growth in the studio based upon individual needs and to foster resilience in the face of imposed gendered assumptions.

Against a backdrop of deep-seated assumptions about pitch in spoken voice observed in various social, experiential and historical disciplines, I draw, in brief, on psychology and evolutionary biological science research in which pitch is associated with evolutionary sexual selection. I also refer to clinical work with transgendered clients documented by Matthew Mills and Gillie Stoneham in their book The Voice Bookfor Trans and Non-Binary People. Finally, I reference instances of historical theatre practice in which pitch is imbricated in the gendered representation of the actor on stage. I suggest that a re-examination of some of the 
hitherto outmoded elocutionary practices in the UK spoken voice lineage has the potential to provide a valuable historical context within which to develop a 'new', gender-aware voice practice.

A mixed methodological approach represents the most effective way to examine the nuanced and entrenched perceptions about the sensations of pitch and the social attitudes that inform them. It also helps to activate a re-purposed place for voice in conservatoire training. The emergent protocol, based on a workshop designed from both a clinical and a Humanities perspective, offers an opportunity to raise greater awareness about the importance of gender inclusivity in the voice studio.

\section{The evidences}

There is biological science research at the University of Sussex that suggests pitch is important at an evolutionary level in sexual selection. The findings are part of a wider scientific picture that indicates pitch is also a significant feature of human perception about gender: 'Pitch is a highly salient feature of the human voice that affects listeners' perception of femininity and masculinity in babies' cries [2], children's speech [11] and adult speech [12]' (Levrero et al. 2018, p. 8).

Further research led by Dr Reby at Sussex, suggests that the sound heard from the infant cry is identified by pre-assigned gender norms when in fact there is no difference in the vocal anatomy of the male or female child until adolescence. In other words, gender is perceived in the cry before there are any anatomical differences to justify this perception: 'low-pitched boys are perceived as more masculine and high-pitched girls are perceived as more feminine' (Reby et al. 2016, p. 1).

Voice is constructed in relation to a number of factors, including cultural and social norms, family custom, individual preference and so on, in ways that are not always conscious. The above research demonstrates that perceptions of pitch, for example, are-from an evolutionary biological perspective-deeply engrained in the cultural infrastructure. As a consequence, not only do we respond to pitch in ways that are gendered but we also produce pitch in relation to gendered conditioning. Both phenomena have repercussions for the kind of attention that can be paid to the voice in public and in private. It is for this reason, therefore, that the training brief in the voice studio needs to both generate awareness about existing preconceptions around pitch and also offer choice beyond the limits of societal assumptions.

Whilst wider investigation about the sex role stereotyping of pitch lies outside the scope of this short discussion, questions raised about the materiality of pitch in vocal practice offer an important first step towards the development of pitch-aware studio-based protocols designed to challenge such gender stereotypes.

\section{New protocols}

What is the practice that has informed a new gender-aware voice studio protocol? A two-part voice workshop series at the Royal Central School of Speech and Drama in February 2018, formed the basis of the research. Designed for MA/MFA Voice students, the series combined theatre voice practice, led by myself, in combination with a clinical voice approach, led by Matthew Mills, a voice coach in a London gender identity clinic. This fusion was instrumental in prompting further consideration about the benefits of self-determined vocal verification and experimentation across all client groups and about the provision of choice in vocal learning. 
The workshop series drew attention to some of the ways in which spoken voice pitch benchmarks get reinforced by gendered assumptions and are subsequently imposed on individual vocal development. It signaled, too, the importance of vocal diagnostics sensitive to gender identity and the ways in which inter-personal learning and self-understanding in a group setting can be beneficial in assisting the self-activated voice over that which is teacherled. It also offered insight into the advantages of a group context in the provision of support for vocal experimentation and the self-determined voice. The findings indicate that pedagogy in the voice studio for actors is enhanced by an adoption of the clinic's mix of group affirmation and confirmation and that clinical voice practice benefits from theatre vocal/pitch experimentation with its exposure of socially-constructed, gender-led vocal benchmarks.

Students interviewed after the two-day workshop, at which a number of anonymised audio recordings of voices from the gender dysphoria clinic were played, affirmed surprise at their own assumptions and demonstrated interest in structuring vocal self-determination into their pedagogy. According to one participant,

[o]ne of the voices that we heard in that second session which, I'm going to use the term, was a very 'masculine' sounding voice but it was a woman speaking and that person was very happy with their voice so actually who are we to say... It's about going 'what does that person actually want?'

Historical theatre practice, too-with its model of voice that falls outside a normative pitch range and goes beyond the bounds of everyday conversation and towards a spectrum of wider vocal extremes-offers insight about pitch use in a contemporary context. The theatre voice student and the trans and gender diverse client can both be deemed to benefit from a wider experiential spectrum as they 'transition' from one vocal state to another.

I am not suggesting that vocal transitioning for the transgender client is equivalent to that of the training actor in scale or temporal urgency. For both, however, there is convergence in an engagement with risk in vocal experimentation as it is associated with both personal and professional identity. Established UK soap actress June Brown, for example, said in a BBC radio interview that it was the 'Johnny one notes' in the actors around her in the early twentyfirst century, who, in shielding themselves from the experience of a full spectrum of sound, revealed their vocal limitations as professionals.

In the interview on the BBC's Radio 4 in February 12th 2017, Brown, spoke about her theatre apprenticeship in the middle of the twentieth century She referenced her experience as an actor in a company with Dame Edith Evans. As a novice, Brown let her pitch drop inaudibly to the floor, and Evans suggested she raise it by copying the excited intonations from the phrase 'I've got the ticket'. She was then advised to use the same pitch movement in the lines from the play: 'Madam, I've seen him'. Upon hearing her successful adjustment, Ms Evans said: 'That's it dear, it's like music. We have to give each other the right notes. I can't do it without you and you can't do it without me.' (Brown, June. 2017, BBC Desert Island Discs).

The remarks made by Evans about the importance of the cooperative vocal act of pitch intonation have relevance beyond theatre. A voice exercise that uses the experience of vibration felt by placing the palm on the sternum of the speaker which is then gestured to a listener, embodies similar cooperative principles. Pitch range, in this way, is both 
experienced and expressed on a self-verified basis because 'felt' and relational at the same time, because shared.

Clearly, there are important evidences to be drawn from historical elocutionary pitch work, particularly as it instructs about the dynamics of vocal expression between giver and receiver. A partnership exercise from early-twentieth-century voice practitioner and founder of Central School of Speech and Drama Elsie Fogerty (1865-1945), in which the speaker is invited to roll out their sound with a light physical swinging gesture, akin to underarm bowling across the floor to a partner at some distance away, adds a further dimension to the work. Students who experienced the exercise in the workshop, offered insight about the level of risk they experienced with regard to whether or not their voice would be received by their partner. The fear was, could it travel that far? They referenced feelings of vulnerability about the attempt to sustain vocal vibration in a pitched vocal arc sufficient enough to make connection with a listening ear and testified to the ways in which, as a demonstrative vocal offer, it exposed their gendered positionality.

When voice practice in both the theatre and the clinic engages with assumptions and aims to move beyond gendered norms, features of personal challenge and risk are shared by participants on both sides. It is important to recognise that, whilst the scale of risk is different for each participant, future protocols will be more effective for both sides if they are mindfully designed around self-verifiable, cooperative and relational vocal principles.

\section{References}

Beard, M., 2017. Women \& power: a manifesto. London: Profile Books.

Bonenfant, Y. (2010). Queer Listening to Queer Vocal Timbres. Performance Research, 15(3), pp.74-80.

Levrero, F., Mathevon, N., Pisanski, K., Gustafsson, E. and Reby, D. 2018. The pitch of babies' cries predicts their voice pitch at age 5. Biology Letters, 14(7), p.8.

Mills, M. and Stoneham, G., 2017. The voice book for trans and non-binary people. London: Jessica Kingsley Publishers.

Mills, M., Stoneham, G. and Georgiadou, I., 2017. Expanding the evidence: Developments and innovations in clinical practice, training and competency within voice and communication therapy for trans and gender diverse people. International Journal of Transgenderism, 18(3), pp.328-342.

Morison, R., 1894. Chambers's elocution, new edition: the readings and recitations selected by R.C.H. Morison. London and Edinburgh: W. \& R. Chambers.

Reby, D., Levréro, F., Gustafsson, E. and Mathevon, N., 2016. Sex stereotypes influence adults' perception of babies' cries. BMC Psychology, 4(1). 